\title{
Seroprevalence of SARS-CoV-2 (COVID-19) among Health Care Workers in Three Health Facilities of Yaounde, Center Region of Cameroon
}

\author{
Philippe Salomon Nguwoh, Akenji Blaise Mboringong, Joseph Fokam, Christian Ngounouh Taheu, \\ Ibrahima Halilou, Stevine Harole Djieudeu Nouwe, Nafissatou Ibnou Moussa, \\ Amina Al-Mayé Bit Younouss, Julienne Louise Ngo Likeng, Désiré Tchoffo, \\ Ghislain René Essomba, Henri Lucien Kamga, and Marie Claire Assoumou Okomo
}

\section{ABSTRACT}

Introduction: Coronavirus Disease 2019 (COVID-19) caused by Severe Acute Respiratory Syndrome Coronavirus 2 (SARS-CoV-2) first appeared in December 2019 in Wuhan, China and has subsequently become a worldwide pandemic. During the pandemic, health care workers (HCWs) were very exposed to COVID-19 infected patients. The aim of this study was to determine seroprevalence of SARS-CoV-2 (COVID-19) among HCWs in three health facilities of Yaounde.

Methods: A cross-sectional study involving $368 \mathrm{HCWs}$ was conducted from January 18th to February 13th, 2021, in three health facilities located in city of Yaounde. Data of study participants were collected by face-to-face interviews using standard questionnaire. Blood samples were collected in labelled dry tubes and analyzed using Rapid Diagnostic Test (RDT) cassettes (Abbott PanbioTMCOVID-19 IgG/IgM Rapid Test Device). The data collected was analyzed using Epi info version 7. Any value of $p<0.05$ was considered statistically significant.

Results: The average age was 30.25 ( $\mathrm{SD} \pm 10.43)$ years old, range from 21 to 72 years old. Overall, the positivity rates of IgM, IgG and IgM+IgG were $6.79 \%(n=25), 17.93 \%(n=66)$ and $1.09 \%(n=4)$ respectively. Multivariate analysis showed that, the rate of IgM positivity was highest in laboratory personnel $(\chi 2=7.99, p=0.3)$ and $\operatorname{IgG}(\chi 2=8.50, p=0.29), \operatorname{IgM}+\operatorname{IgG}(\chi 2=1.92$, $p=0.26)$ respectively in pharmacy and clinical personnel. The clinical signs such as fever $\left(>38^{\circ} \mathrm{C}\right)$ or history of fever was statistically significant with IgM $(\chi 2=11.71, p=0.0006)$ while, sore throat was statistically significant associated with $\operatorname{IgM}(\chi 2=14.3, p=0.0008)$ and $\operatorname{IgG}(\chi 2=6.33, p=0.04)$.

Conclusion: The results of this study reveal a high seroprevalence of circulation of the virus in hospital milieu in Yaounde suggesting the continuation of the COVID-19 « Track-Test-Treat » system to break the chain of transmission.

Keywords: Health care workers, seroprevalence, SARS-CoV-2, Yaounde
Submitted : October 15, 2021

Published : December 13, 2021

ISSN: $2593-8339$

DOI: 10.24018 /ejmed.2021.3.6.1109

P. S. Nguwoh*

Distant Production House University, Delaware, USA.

(e-mail:

pilippesalomonguwoh@ gmail.com)

A. B. Mboringong

National Public Health Laboratory,

Yaoundé, Cameroon.

(e-mail: blaiseake@gmail.com)

J. Fokam

University of Buea, Yaoundé, Cameroon.

(e-mail: josephfokam@gmail.com)

C. N. Taheu,

Higher Institute of Sciences and Techniques Applied to Health, University of Douala, Yaoundé, Cameroon.

(e-mail: taheuchristian@gmail.com)

I. Halilou,

National Public Health Laboratory,

Yaoundé, Cameroon.

(e-mail: ib100yaya@gmail.com)

S. H. D. Nouwe

Higher Institute of Sciences and

Techniques Applied to Health, University

of Douala, Yaoundé, Cameroon.

(e-mail: haroldnouwe@gmail.com)

N. I. Moussa

National Public Health Laboratory,

Yaoundé, Cameroon.

(e-mail: nafy88@yahoo.fr)

A. Al-Mayé Bit Younouss

National Public Health Laboratory,

Yaoundé, Cameroon.

(e-mail: bityounoussamina@yahoo.fr)

J. L. N. Likeng

Catholic University of Central Africa,

Yaoundé, Cameroon.

(e-mail: likeng12@yahoo.com)

D. Tchoffo

Distant Production House University,

Delaware, USA.

(e-mail: dtchoffo@yahoo.fr)

G. R. Essomba

University of Yaoundé 1, Yaoundé

Cameroon.

(e-mail: r esso@yahoo.fr)

H. L. Kamga

University of Dschang, Cameroon

(e-mail: henrikamga2002@yahoo.fr)

M. C. A. Okomo

University of Yaoundé 1, Yaoundé

Cameroon.

(e-mail: okomo2015@yahoo.fr

*Corresponding Author 


\section{INTRODUCTION}

Since December 2019, COVID-19 caused by SARS-CoV2 has become a Public Health Emergency of International Concern. First appearing in Wuhan, capital of Hubei province in Republic of China, the COVID-19 epidemic has spread rapidly around the world [1], [2]. With an estimated prevalence of 37 million cases infected with COVID-19, including 1 million deaths on October $9^{\text {th }}, 2020$, the epidemic was declared as a global pandemic on March $11^{\text {th }}, 2020$, by the World Health Organization (WHO) [2], [3]. Thus, as $28^{\text {th }}$, 2021, more than 110 million people were affected by this disease and more than 2.5 million people have died from the COVID-19 pandemic [4].

Despite these alarming prevalence, sub-Sahara Africa (SSA) remains until the zone which records a low rate of cases of COVID-19 and especially with a very low mortality compared to other regions of the world [3]. Located in SSA, Cameroon recorded the first case of COVID-19 on March $06^{\text {th }}, 2020$. Since that time, we have witnessed an exponential growth in the number of people infected with COVID-19 and the spread of the pandemic to all ten administrative regions of the country making Cameroon the fourth most affected country in SSA with 22.103 cumulative cases and 429 deaths (behind South Africa, Nigeria, and Ethiopia) [5]. Moreover, as of February $18^{\text {th }}, 2021$, the country has registered approximately 32.681 WHO-confirmed cases [6].

SARS-CoV-2 infection is spread through respiratory droplets, contact with contaminated fluids, and surfaces contaminated with the virus [7]. Moreover, asymptomatic people are likely to transmit the infection, and people who have not reported being in the vicinity of a known case have also been infected [8]. To contain the spread of COVID-19, by following the barrier measures (compulsory wearing face masks, social distancing, hand hygiene, etc.) recommended by the WHO, Cameroon has drawn up a response plan, revised in 2020 which revolves around epidemiological surveillance, management of infected cases, social regulation, governance and coordination [9].

Since the onset of the COVID-19 pandemic, the activity sector that remains the most affected has been the hospital milieu. Although important for the functioning of health systems, HCWs constitute the first barrier to SARS -CoV-2. Health care workers are exposed to several challenges: exhaustion, difficult sorting of patients, family separation and stigmatization [10]. These HCWs continually face a high increased risk of infection by direct contact by caring for a high number of patients infected with COVID-19 or by indirect contact with samples and waste, especially if the means of personal protection are insufficient [11]. The International Council of Nurses estimates that $90.000 \mathrm{HCWs}$ are infected worldwide. In the Republic of China, 2055 hospital workers working in 476 hospitals have been reported to have been infected [12]. Several studies carried out in Italy and United States of America (USA) reported infection rates among HCWs of $10 \%$ and $19 \%$ respectively, the death rate reaching $1.2 \%$ [13]. Furthermore, other studies have shown that the lethal burden of COVID-19 infection is proportional to the resilience of health care systems [14]. Diagnosing people exposed or infected with the coronavirus is essential to controlling the global COVID-19 pandemic in places where the disease has spread. For this, it is important to estimate the prevalence of the disease in order to assess herd immunity and virus circulation [15], [16]. With the outbreak of the pandemic which continues to claim new victims, especially with the new Delta variant, Cameroon has opted for mass screening by rapid diagnostic tests (RDTs) to isolate not only positive cases, symptomatic or asymptomatic, but also those who have had previous contact with SARS-CoV2.

To our knowledge, information on SARS-CoV-2 seroprevalence among HCWs in Africa such as Cameroon is insufficient. In August 2020, $780 \mathrm{HCWs}$ had been infected with SARS-CoV-2 and 21 deaths were recorded in Cameroon [17]. A study conducted in Republic Democratic of Congo shows a seroprevalence of $21.8 \%$ among medical personnel [16]. Moreover, the study carried out in Cameroon by Fai and collaborators [18] found a seroprevalence of $20 \%$ for $\operatorname{IgM}$ and $24 \%$ for $\operatorname{IgG}$ in the general population with the levels of $\operatorname{IgM}$ $(5.3 \%)$ and $\operatorname{IgG}(2.3 \%)$ in health personnel. It is therefore necessary to carry out new investigations on the circulation of the coronavirus in hospitals.

\section{Methodology}

\section{A. Study Design and Participants}

From January 18th to February 13th, 2021, we conducted a multicenter cross-sectional study among $368 \mathrm{HCWs}$ in three health facilities (Nkolndongo health district, Biyem-assi health district, and Djoungolo health district) in city of Yaoundé. During the COVID-19 pandemic, these three health facilities were among the health facilities which recorded high numbers of confirmed COVID-19 cases. The study aim was well explained to all the participants and those who agreed to participate were recruited consecutively. Data were collected using a structured questionnaire including information such as: sex, age, health service, history of COVID-19 symptoms.

\section{B. Ethics Approval and Consent to Participate}

Research proposal was evaluated, and the ethical clearance was obtained from the Institutional Review Board (IRB) of the Centre Regional Ethics Committee for Human Health Research ( $\mathrm{N}^{\circ}$ : $1939 / \mathrm{CRERSHC} / 2020$ from $29^{\text {th }}$ December 2020). Also, the administrative authorization was issued by the Centre Regional Delegation of Public Health $\left(\mathrm{N}^{\circ}\right.$ : 3285/AP/MINSANTE/SG/DRSPC/CRERSH from $13^{\text {th }}$ January 2021). Additionally, we obtained authorization from the directors of the three health facilities selected. An information note was given to all the eligible participants, who then provided their written informed consent prior to enrollment into the study. The confidentiality of study participants was secured by the use of identification codes.

\section{Determination of Minimum Sample Size}

The minimum sample size was obtained using the standard formula:

$$
\mathrm{n}=\mathrm{z}^{2} \mathrm{p}(1-\mathrm{p}) / \mathrm{m}^{2},
$$

with " $z$ " = the standard deviation of 1.96 (95\% confidence interval); "p"= seroprevalence of SARS-CoV-2 antibodies found in Cameroon (IgM: 20\% and IgG: 24\%) [18], "m"=degree of precision (0.05) and " $\mathrm{n} "=$ minimum sample size. 


\section{Blood Sample Collection and Conservation}

Four milliliters $(4 \mathrm{ml})$ of whole blood were collected aseptically from each study participant by venipuncture and transferred into a sterile labeled dry container. The blood sample was centrifuged at $1.500 \mathrm{rpm}$ for five minutes. Serum was separated and stored at $-20^{\circ} \mathrm{C}$ in $1.5 \mathrm{ml}$ microtubes until time of analysis.

\section{1) Detection of SARS-CoV-2 Specifics Antibodies ( $\operatorname{Ig} G / \operatorname{IgM})$}

SARS-CoV-2 antibodies (IgG/IgM) were detected in sera using RDT Abbott (Panbio ${ }^{\mathrm{TM}}$ COVID-19 IgG/IgM Rapid Test Device, REF: ICO-T40203, LOT: COV0052131, Expiration: 2021-04-30) according to the manufacturer's instructions. The Panbio ${ }^{\text {TM }}$ COVID-19 IgG/IgM Rapid Test is an immunochromatographic lateral flow test kit used for the qualitative detection of IgG and IgM antibodies to SARSCoV-2 in human serum, plasma, venous and capillary whole blood. The Abbott SARS-CoV-2 IgG/IgM test is reported to have a specificity of $99.4 \%$ and a sensitivity of $98.2 \%$ [19]. The test is interpreted 10-20 minutes after sample application.

Positive IgM result was reported when two distinct red lines appear (one line in the control zone "C" and another in the test zone "M"). For positive result (IgG positive), two distinct red lines appear (one line in the control zone " $\mathrm{C}$ " and another in the test zone "G"). Negative result shows the appearance of one red line only in control zone " $\mathrm{C}$ " and no appearance of red line in test zone $\mathrm{M}$ and $\mathrm{G}$.

\section{2) Quality Control}

The test device has a test line $(\mathrm{M} / \mathrm{G})$ and a control line (C). The control line (C) is used for procedural control and should always appear if the test procedure is performed properly and the test reagents of the control line are working. In addition, the test used was performed using control samples (positive and negative) available in the National Public Health Laboratory (NPHL) serum bank. These control samples had previously been confirmed by Enzyme Linked Immunosorbent Assay (ELISA) technique.

\section{E. Data Collection and Statistical Analysis}

The data were collected using a standard questionnaire as well as those obtained in the laboratory after analysis of the samples were summarized in a Microsoft Excel software version 2013 spreadsheet, then concluded and analyzed with the software Epi info version 7. Statistics were performed using chi-square $(\chi 2)$ with Yates correction (significance level $\mathrm{p}<0.05$ ) and with a $95 \%$ confidence interval.

Quality of data before analysis: The tests were all performed by trained laboratory personnel and questionnaires were verified for completeness and consistency by the principal investigator before statistical analysis.

\section{F. Study Limitation}

The principal limitation of this study, is the type RDT used to detect SARS-CoV-2 in the collected sera. The reagents used were designed for qualitative screening and consequently. The concentration of SARS-CoV-2 could not be determined. Moreover, serologic tests are limited by false positivity because of cross-reactions [19]. Also, a large number of study participants were ultimately excluded due to the incompletely captured information. Furthermore, the type of study (cross-sectional) did not allow us to evaluate the cases of comorbidities, clinical signs, the contact between healthcare workers and COVID-19 infected patients.

\section{RESUlts}

\section{A. General Characteristics of Study Participants}

A total of $368 \mathrm{HCWs}$ in three health facilities was surveyed between January $18^{\text {th }}$ to February $13^{\text {th }}, 2021$ of Yaoundé. Female were more represented with 227 of $368(61.68 \%)$ versus (vs.) 141 of 368 (38.32\%) for males, with a male: female sex ratio of 0.6 . Study participants average age, \pm standard deviation was $30.25 \pm 10,43$ years old, range from 21 to 72 years old, with majority of study participants younger less than age 32 years (269 of 368; 73.10\%). Classified by health service, laboratory personnel were more represented making up 85 of the 368 participants $(23.10 \%)$, followed by clinical personnel (55 of $368 ; 14.95 \%$ ). Based on clinical presentation, 313 of $368(85.05 \%)$ were asymptomatic and 55 of $368(14.95 \%)$ were symptomatic (TABLE I).

TABLE I: GENERAL CHARACTERISTICS OF STUDY PARTICIPANTS

\begin{tabular}{|c|c|c|}
\hline Variables & $\begin{array}{c}\text { Percentage } \\
(\%)\end{array}$ & $\begin{array}{c}\text { Total number of } \\
\text { participants } \\
(\mathrm{N}=368)\end{array}$ \\
\hline \multicolumn{3}{|c|}{ Sex } \\
\hline $\begin{array}{l}\text { Female, mean age: } \\
29.89 \pm 10.51 \text { years old }\end{array}$ & 61.68 & 227 \\
\hline $\begin{array}{c}\text { Male, mean age: } 30.82 \pm 10.31 \\
\text { years old }\end{array}$ & 30.32 & 141 \\
\hline \multicolumn{3}{|c|}{ Age group in years (min-max: 21-72) } \\
\hline $21-31$ & 73.10 & 269 \\
\hline $32-42$ & 14.13 & 52 \\
\hline $43-53$ & 7.61 & 28 \\
\hline $54-64$ & 3.53 & 13 \\
\hline $65+$ & 1.63 & 6 \\
\hline \multicolumn{3}{|c|}{ Health service } \\
\hline Reception & 5.98 & 22 \\
\hline Administration & 11.41 & 42 \\
\hline External consultation & 8.97 & 33 \\
\hline Hygiene & 11.96 & 44 \\
\hline Physiotherapy & 12.50 & 46 \\
\hline Laboratory & 23.10 & 85 \\
\hline Clinical & 14.95 & 55 \\
\hline Pharmacy & 11.14 & 41 \\
\hline \multicolumn{3}{|c|}{ Presence of symptoms } \\
\hline No & 85.05 & 313 \\
\hline Yes & 14.95 & 55 \\
\hline
\end{tabular}

\section{B. Seroprevalence of SARS-CoV-2 among Study Population}

Out of 368 HCWs sera tested, 25 (6.79\%, 95\%CI: 4.649.84) were IgM positive, 66 (17.93\%; 95\%CI: 14.35-22.18) HCWs were tested positive for IgG and 4 (1.09\%; 95\%CI: $0.42-2.76)$ were positive for both $\operatorname{IgM}$ and $\operatorname{IgG}$. 


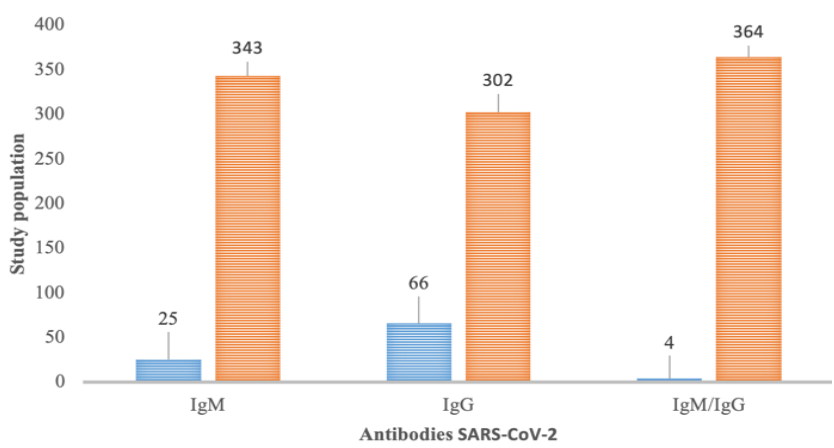

Fig. 1. Seroprevalence of antibodies SARS-CoV-2 among study population.

\section{Seroprevalence of Antibodies SARS-CoV-2 among $\mathrm{HCWS}$}

Regarding the sex, the rate of IgM was higher in males $(9.22 \%)$ vs. $3.52 \%$ for the female $(\mathrm{p}=0.1)$ while the rate of IgG was higher in females $(42 / 66 ; 18.50 \%)$ vs. $24 / 66$ $(17.02 \%)$ for males $(\mathrm{p}=0.71)$. The seroprevalence of $\operatorname{IgM}$ decreased with age group $(\mathrm{p}=0.96)$. The seroprevalence of IgM was higher in HCWs with symptoms (9.09\%) vs. 5.11\% for those who did not have symptoms $(\mathrm{p}=0.24)$. Meanwhile, the seroprevalence of IgG was higher in the 21-31years age group with 50 out of 66 (18.59\%). Classified by health service, the seroprevalence of $\operatorname{IgM}$ was highest in laboratory personnel $(\mathrm{p}=0.3)$. Immunoglobulin $\mathrm{G}(\mathrm{IgG})$ seroprevalence was highest in pharmacy personnel $(\mathrm{p}=0.29)$ while, $\operatorname{IgM}+\operatorname{IgG}$ seroprevalence was highest in clinical personnel $(p=0.26)$ as shown in TABLE II.

D) Seroprevalence of SARS-CoV-2 Antibodies (IgM and $\operatorname{IgG)}$ and Clinical Signs

The Table III shows that, clinical signs such as fever or history fever was statistically significant associated with IgM SARS-CoV-2 ( $p=0.0006)$ while, sore throat was statistically significant associated with anti-IgM SARS-CoV-2 $\mathrm{p}=$ $0.0008)$ and IgG SARS-CoV-2 ( $\mathrm{p}=0.04)$.

TABLE II: SEROPREVALENCE OF ANTIBODIES SARS-COV-2 AMONG HCWS

\begin{tabular}{|c|c|c|c|c|c|c|}
\hline 0 & $\begin{array}{c}\text { IgM (+ve) } \\
25(\%) \\
\end{array}$ & $\begin{array}{c}\chi^{2} \\
\text { p-value }\end{array}$ & $\begin{array}{c}\text { IgG (+ve) } \\
66(\%) \\
\end{array}$ & $\begin{array}{c}\chi^{2} \\
\text { p-value }\end{array}$ & $\begin{array}{c}\text { IgM and IgG (+ve }) \\
4(\%) \\
\end{array}$ & $\begin{array}{c}\chi^{2} \\
\text { p-value }\end{array}$ \\
\hline & & & Sex & & & \\
\hline Female & $12(5.29)$ & $\chi^{2}=2.12$ & $42(18.50)$ & $\chi^{2}=0.12$ & $4(1.76)$ & $\chi^{2}=1.14$ \\
\hline Male & $13(9.22)$ & $\mathrm{p}=0.1$ & $24(17.02)$ & $\mathrm{p}=0.71$ & $0(0.0)$ & $\mathrm{p}=0.28$ \\
\hline \multicolumn{7}{|c|}{ Age group in years } \\
\hline $21-31$ & $19(7.06)$ & $\chi^{2}=1.01$ & $50(18.59)$ & $\chi^{2}=3.14$ & $2(0.63)$ & $\chi^{2}=4.04$ \\
\hline $32-42$ & $4(7.69)$ & $\mathrm{p}=0.96$ & $9(17.31)$ & $\mathrm{p}=0.6$ & $0(0.00)$ & $\mathrm{p}=0.39$ \\
\hline $43-53$ & $1(3.57)$ & & $4(14.29)$ & & $1(3.57)$ & \\
\hline $54-64$ & $1(7.69)$ & & $1(7.69)$ & & $1(7.69)$ & \\
\hline $65+$ & $0(0.00)$ & & $2(40.0)$ & & $0(0.00)$ & \\
\hline \multicolumn{7}{|c|}{ Health service } \\
\hline Reception & $0(0.0)$ & $\chi^{2}=7.99$ & $5(22.73)$ & $\chi^{2}=8.50$ & $0(0.0)$ & $\chi^{2}=1.92$ \\
\hline Administration & $4(9.52)$ & $\mathrm{p}=0.3$ & $9(21.43)$ & $\mathrm{p}=0.29$ & $1(2.38)$ & $\mathrm{p}=0.26$ \\
\hline $\begin{array}{c}\text { External } \\
\text { consultation }\end{array}$ & $1(3.03)$ & & $5(15.15)$ & & $0(0.0)$ & \\
\hline Hygiene & $0(0.0)$ & & $12(27.27)$ & & $0(0.0)$ & \\
\hline Physiotherapy & $3(6.52)$ & & $10(21.74)$ & & $0(0.0)$ & \\
\hline Laboratory & $8(9.41)$ & & $9(10.59)$ & & $1(1.18)$ & \\
\hline Medical & $5(9.09)$ & & $7(12.73)$ & & $2(3.64)$ & \\
\hline Pharmacy & $4(9.76)$ & & $9(21.95)$ & & $0(0.0)$ & \\
\hline \multicolumn{7}{|c|}{ Presence of symptoms } \\
\hline No & $19(6.07)$ & $\chi^{2}=1.72$ & $59(18.85)$ & $\chi^{2}=1.19$ & $3(0.96)$ & $\chi^{2}=0.019$ \\
\hline Yes & $6(10.91)$ & $\mathrm{p}=0.2$ & $7(12.73)$ & $\mathrm{p}=0.27$ & $1(1.82)$ & $\mathrm{p}=0.89$ \\
\hline
\end{tabular}

+ve: positive; $\%$ : percentage; $p=p$-value; $\chi 2=$ Chi-square.

TABLE III: SEROPREVALENCE OF ANTI-IGM/IGG SARS-COV-2 AND CLINICAL SIGNS

\begin{tabular}{|c|c|c|c|c|c|c|}
\hline \multicolumn{2}{|c|}{ Variables } & \multirow{2}{*}{$\begin{array}{c}\begin{array}{c}\text { Total number of } \\
\text { participants } \\
(\mathrm{N}=368)\end{array} \\
359\end{array}$} & \multirow{2}{*}{$\begin{array}{c}\text { IgM (+ve) } \\
25(\%) \\
23(6.41)\end{array}$} & \multirow{2}{*}{$\begin{array}{c}\begin{array}{c}\chi^{2} \\
\text { p-value }\end{array} \\
\chi^{2}=1.42\end{array}$} & \multirow{2}{*}{$\begin{array}{c}\operatorname{IgG}(+\mathrm{ve}) \\
66(\%) \\
63(75.0)\end{array}$} & \multirow{2}{*}{$\begin{array}{c}\begin{array}{c}\chi^{2} \\
\text { p-value }\end{array} \\
\chi^{2}=0.60\end{array}$} \\
\hline Runny nose & No & & & & & \\
\hline & Yes & 9 & $2(25.00)$ & $\mathrm{p}=0.23$ & $3(25.0)$ & $\mathrm{p}=0.43$ \\
\hline \multirow{4}{*}{$\begin{array}{c}\text { Shortness of } \\
\text { breath } \\
\text { Tired }\end{array}$} & No & 367 & $25(6.81)$ & $\chi^{2}=0.00$ & $66(17.98)$ & $\chi^{2}=0.00$ \\
\hline & Yes & 1 & $0(0.00)$ & $\mathrm{p}=1.0$ & $0(0.00)$ & $\mathrm{p}=1.0$ \\
\hline & No & 345 & $23(6.67)$ & $\chi^{2}=0.00$ & $65(18.84)$ & $\chi^{2}=2.17$ \\
\hline & Yes & 23 & $2(8.69)$ & $\mathrm{p}=1.0$ & $1(4.35)$ & $\mathrm{p}=0.14$ \\
\hline \multirow{4}{*}{$\begin{array}{c}\text { Fever }\left(>38^{\circ} \mathrm{C}\right) \text { or } \\
\text { history of fever } \\
\text { Chills }\end{array}$} & No & 362 & $22(6.08)$ & $\chi^{2}=11.71$ & $65(17.95)$ & $\chi^{2}=0.00$ \\
\hline & Yes & 6 & $3(50.00)$ & $\mathrm{p}=0.0006^{* *}$ & $1(16.67)$ & $\mathrm{p}=1.0$ \\
\hline & No & 343 & $25(7.29)$ & $\chi^{2}=0.14$ & $66(19.24)$ & $\chi^{2}=0.43$ \\
\hline & Yes & 25 & $0(0.00)$ & $\mathrm{p}=1.0$ & $0(0.00)$ & $\mathrm{p}=1.0$ \\
\hline \multirow[t]{2}{*}{ Sore throat } & No & 360 & $25(6.94)$ & $\chi^{2}=14.3$ & $66(18.33)$ & $\chi^{2}=6.33$ \\
\hline & Yes & 8 & $0(0.00)$ & $\mathrm{p}=0.0008 * *$ & $0(0.00)$ & $\mathrm{p}=0.04 * *$ \\
\hline \multirow{2}{*}{ Headache } & No & 340 & $25(7.35)$ & $\chi^{2}=1.20$ & $64(18.82)$ & $\chi^{2}=1.67$ \\
\hline & Yes & 28 & $0(0.00)$ & $\mathrm{p}=0.27$ & $2(7.14)$ & $\mathrm{p}=0.2$ \\
\hline \multirow[t]{2}{*}{ Loss of appetite } & No & 366 & $25(6.83)$ & $\chi^{2}=0.00$ & $66(18.03)$ & $\chi^{2}=0.00$ \\
\hline & Yes & 2 & $0(0.00)$ & $\mathrm{p}=1.0$ & $0(0.00)$ & $\mathrm{p}=1.0$ \\
\hline \multirow{2}{*}{$\begin{array}{c}\text { Loss of sense of } \\
\text { smell }\end{array}$} & No & 367 & $25(6.81)$ & $\chi^{2}=0.00$ & $66(17.98)$ & $\chi^{2}=0.00$ \\
\hline & Yes & 1 & $0(0.00)$ & $\mathrm{p}=1.0$ & $0(0.00)$ & $\mathrm{p}=1.0$ \\
\hline \multirow[t]{2}{*}{ Cough } & No & 340 & $22(6.47)$ & $\chi^{2}=0.7$ & $61(17.94)$ & $\chi^{2}=0.0001$ \\
\hline & Yes & 28 & $3(10.71)$ & $\mathrm{p}=0.64$ & $5(17.86)$ & $\mathrm{p}=0.9$ \\
\hline \multirow[t]{2}{*}{ Diarrhea } & No & 363 & $24(6.61)$ & $\chi^{2}=1.46$ & $66(18.03)$ & $\chi^{2}=0.00$ \\
\hline & Yes & 5 & $1(20.0)$ & $\mathrm{p}=0.4$ & $0(0.00)$ & $\mathrm{p}=1.0$ \\
\hline
\end{tabular}

+ve: positive; -ve: negative ; \%: percentage ; $\mathrm{p}=\mathrm{p}$-value ; $\chi 2=$ Chi-square ; $* *$ Statistically significant. 


\section{DisCUSSION}

This study was conducted to determine seroprevalence of COVID-19 among HCWs in three selected health facilities of Yaounde. Serological surveys are a better tool to determine the spread of an infectious disease, especially in the presence of asymptomatic cases or incomplete investigation of those with symptoms.

In all, 87/368 (23.64\%) HCWs were tested positive for SARS-CoV-2 antibodies. Among them, 25 (6.79\%) were tested for anti-SARS-CoV-2 IgM positive, 66 (17.93\%) were tested positive for anti-SARS-CoV-2 IgG and 4 (1.09\%) were tested positive for both antibodies (IgM and $\mathrm{IgG}$ ). This finding reveals a circulation of coronavirus in hospital milieu due to the contact between HCWs and COVID-19 infected patients. Although our study concerned only health personnel, our results are similar to those of Fai and collaborators [18], who found IgG seroprevalence of $24 \%$ (CI95\%: 20-27) in the general population, witness to previous contact with the virus. Nevertheless, in the same study, Fai and collaborators found low levels of $\operatorname{IgM}(5.3 \%)$ and $\operatorname{IgG}$ $(2.3 \%)$ antibodies in HCWs. This could be justified on the one hand by the fact that the study of Fai and collaborators was carried out in June 2020, when the epidemiological situation of COVID-19 had reached its peak in Cameroon. On the other hand, by the fact that $10 \%$ of the study population were hospitalized patients. In addition, this difference could be justified by the sample size of our study, unlike that of Fai and collaborators (368 vs. 1192). Similar results in Republic Democratic of Congo shows a seroprevalence of $21.8 \%$ among medical personnel [16]. These findings are high than that reported in Span and USA among HCWs [20], [21]. These results could be likewise explicated to the fact that, our study used RDTs to track HCWs.

Immunoglobulin $\mathrm{M}$ (IgM) was more observed in the male $(9.22 \%)$ vs. $3.52 \%$ for the female reflecting the primoinfection to coronavirus. Similar findings were observed by Fai and collaborators [19] who found a statistical association between gender and antibody positivity $\operatorname{IgM}$ with higher prevalence in male. The sex was not statistically associated to immunoglobulin $\mathrm{G}$ (IgG). Our results diverge from what was reported by Fai and collaborators who found a statistical association between gender and antibodies. This can be explaining by sample size (368 vs. 1192). The rate of IgM decreased with age group and this rate was more recorded in HCWs with symptoms $(9.09 \%)$ and $5.11 \%$ for those who did not have symptoms $(p=0.24)$. Meanwhile, the rate of $\operatorname{IgG}$ was more observed in group age of 21-31 years old with 50 on 66 $(18.59 \%)$.

Our results showed that the IgM antibody level sign of recent contact with the virus was more observed in laboratory personnel, pharmacy and clinical personnel. Despite the fact that the results obtained are not statistically significant, the statistic remains that during the COVID-19 pandemic, HCWs were furthermost exposed. This could be explained by the fact that, on the one hand, laboratory staff collected and handled samples from infected patients and, on the other hand, the contact between patients and medical doctor. The contamination could be due to the failure to respect the distance between healthcare staff and between patients, by wearing a face mask, washing hands, which are the barrier measures to prevent the disease. According to Shneider and collaborators [22] the outburst of contamination among health personnel observed in their study was mainly explicated by transmission between hospital personnel.

The level of $\operatorname{IgG}$ antibodies, revealing of previous contact with SARS-CoV-2, was mostly found among hygiene managers and reception staff waste from the various departments. Consequently, it could become contaminated when managing this waste, especially since in our context personal protective equipment (PPE) is insufficient and in most cases unsuitable. For the reception staff, we found the old contact cases with the virus. Most of the reception staff are non-clinical, and hygiene staff at the onset of the pandemic were the first alert. Through inappropriate equipment, they were in contact with the sick and the waste. Thus, all suspected COVID-19 cases go through reception. Although contact between patients and staff does not last long, the risk of transmission remains. Olivier and collaborators [23] published a study based on an online questionnaire intended for health personnel, the preliminary results showed a lack of use of protective measures, especially for professionals working in the private sector. Therefore, the authors conclude that the role of contamination between caregivers at their place of practice is an important determinant in the spread of the disease. Furthermore, the study of Wei and collaborators [12] compared COVID-19 infection between health workers and a control group (general population), they found a higher rate of infection among hospital workers, but the mortality and the rate of severe forms were lower in this group suggesting the vulnerability of medical personnel to COVID-19 infection.

\section{CONCLUSION}

This study was conducted to determine seroprevalence of SARS-CoV-2 among HCWs during the COVID-19 pandemic and it reveal a high seroprevalence of SARS-CoV2 (COVID-19) among HCWs in the three selected health facilities in the city of Yaounde. Clinical signs such as fever or history fever and sore throat were associated with COVID19. Improving measures to protect HCWs against COVID-19 infected patients is essential. The data from this study suggest the continuation of the COVID-19 "track-test-treat" system in order to break the chain of transmission.

\section{RECOMMENDATION}

Cameroon continues to register new cases of sickness and death from COVID-19. With the emergence of new variants such as the Delta variant, it is necessary to continue to respect barrier measures (wearing face masks, social biological distancing, general hygiene etc.) recommended by the WHO and the Centers for Disease Control and Prevention. With regard to HCWs, it is important to strengthen protective measures by providing standard personal protective equipment (PPE). In addition, large-scale vaccination of health personnel is recommended in order to limit the spread of the virus.

\section{ACKNOWLEDGMENT}

The authors would like to thank all the study participants who give the inform consent to participate in this study. We would like also to acknowledge the following persons without whom the research would not have been possible: $M$ Lembe Mbake Thomas, Yuosembom Emile Keming, Solange 
Pefouakeu Pepa, Jerome Tchuisseu Ngantchui, Mme Bih Caroline, M Tchualeu Kameni Albert Bertrand, M Mfouapon Wouandji Alassa, M Mbarga Foe Marcel, Mme Bete Nyembe Gisèle, Dr Inenguini Bertrand, Dr Olomo Thérèse, Mme Ngo Ndouga Marie, and Mme Raffic Angeline.

\section{REFERENCES}

[1] Lu H, Stratton CW, Tang YW. Outbreak of pneumonia of unknown etiology in Wuhan China: the mystery and the miracle. Journal of Medical Virology. 2020; 92(4): 401.

[2] Cucinotta D, Vanelli M. WHO Declares COVID-19 a Pandemic. Acta Biomedica. 2020; 91(1): 157-160.

[3] World Health Organization. Coronavirus disease (COVID-19). [Online] 2020 [cited on: 2020 October 11].

[4] $\mathrm{Wu} \mathrm{C}$, Chen X, Cai Y, et al. Risk factors associated with acute respiratory distress syndrome and death in patients with coronavirus disease 2019 pneumonia in Wuhan, China. JAMA Intern Med 2020; in press [https://doi.org/10. 1001/jamainternmed.2020.0994].

[5] Johns Hopkins University. Coronavirus Covid-19 Global cases by the Center for Systems Science and Engineering (CSSE) at Johns Hopkins University (JHU). [Online] Available from: https://coronavirus.jhu.edu/map.html

[6] WHO. Rapport de situation épidémiologique du SARS-CoV-2 [Online] 2021 [cited on: 2021 February 26]. Available from : https://www.who.int/emergencies/diseases/novel-coronavirus2019/situation-reports/.

[7] Chan JFW, Yuan S, Kok KH, To KKW, Chu H, Yang J, et al. A familial cluster of pneumonia associated with the 2019 novel coronavirus indicating person-to-person transmission: a study of a family cluster. Lancet. 2020; 395(10223): 514-23.

[8] Rothe C, Schunk M, Sothmann P, Bretzel G, Froeschl G, Wallrauch C, et al. Transmission of 2019-nCoV infection from an asymptomatic contact in Germany. New England Journal Medicine. 2020; 382: 970971.

[9] CCOUSP. Stratégies nationales de diagnostic et de dépistage de la COVID-19 au cameroun. [Online] 2020.

[10] Chersich MF, Gray G, Fairlie L, Eichbaum Q, Mayhew S, Allwood B et al. COVID-19 inAfrica: care and protection for frontline healthcare workers. Global Health. 2020; 16(1): 46.

[11] OMS. Utilisation rationnelle des équipements de protection individuelle (EPI) contre la maladie à coronavirus 2019 (COVID-19) et éléments à considérer en cas de grave pénurie consulté le 4 Avril. [Online] 2020. Available from: https://apps.who.int/iris/bitstream/handle/10665/331765/WHO-2019nCov-IPC PPE use2020.3-fre.pdf.

[12] Wei JT, Liu ZD, Fan ZW, Zhao L, Cao WC. Epidemiology of and risk factors for COVID-19 infection among health care workers: a multicentre comparative study. International Journal of Environmental Research and Public Health. 2020;17(19): 7149.

[13] Ağalar C, Öztürk Engin D. Protective measures for COVID-19 for healthcareproviders and laboratory personnel. Turkish Journal of Medical Sciences. 2020; 50(SI-1): 578-84.

[14] Ji Y, Ma Z, Peppelenbosch MP, Pan Q. Potential association between COVID-19 mortality and health-care resource availability. The Lancet Global Health. 1 avril ;8(4): e48

[15] Xiao J, Fang M, Chena Q, He B. SARS, MERS and COVID-19 among healthcare workers: a narrative review. 2020; 13(6): 843-848.

[16] Katchunga PB, Murhula A, Akilimali P, Zaluka JC, Karhikalembu R, Makombo M, et al. Séroprévalence des anticorps anti-SARS-CoV-2 parmi les voyageurs et travailleurs dépistés à la clinique Saint Luc de Bukavu, à l' Est de la République Démocratique du Congo, de mai en août 2020. The Pan African Medical Journal. 2021: 38. French.

[17] Nguépy KFR, Mboua PC, Tadongfack DT, Tchoffo FE, Tatang TC, Zeuna JI, et al. Psychological distress among health care professionals of the three COVID-19 most affected Regions in Cameroon: Prevalence and associated factors. Annales Médico-Psychologiques. 2021; 179: 141-146.

[18] Fai KN, Corine TM, Bebell LM, Mboringong AB, Nguimbis EBPT, Nsaibirni R, et al. Serologic response to SARS-CoV-2 in an African Population. Scientific African, 2021; e00802.

[19] Batra R, Olivieri LG, Rubin D, Vallari A, Pearce S, Olivo A, et al. A comparative evaluation between the Abbott Panbio ${ }^{\text {TM }}$ COVID-19 $\mathrm{IgG} / \mathrm{IgM}$ rapid test device and Abbott Architect ${ }^{\mathrm{TM}}$ SARS CoV-2 IgG assay. Journal of Clinical Virology. 2020; 132.

[20] Suarez-Garcıa I, Martınez de Aramayona Lopez MJ, Saez Vicente A, Lobo Abascal P. SARS-CoV-2 infection among healthcare workers in a hospital in Madrid, Spain. Journal of Hospital Infection 106 (2020) 357e363. Available online at www.sciencedirect.com

[21] Moscola J, Sembajwe G, Jarrett M, Farber B, Chang T, Thomas McGinn T, et al. Prevalence of SARS-CoV-2 Antibodies in Health Care Personnel in the New York City Area. JAMA. 2020; 324(9): 893895.

[22] Schneider S, Piening B, Pauline Pasovsky A.N, Krüger AC, Gastmeier $\mathrm{P}$, and Aghdassi SJS. SARS-Coronavirus-2 cases in healthcare workers may not regularly originate from patient care: lessons from a university hospital on the underestimated risk of healthcare worker to healthcare worker transmission. Antimicrob Resist Infect Control (2020) 9:192. https://doi.org/10.1186/s13756-020-00848-w

[23] Olivier C, Bouvet E, Abiteboul D, Lolom I, Pellissier G, DelarocqueAstagneau E. et al. Contexte de contamination des professionnels de santé par la COVID-19 : résultats préliminaires. Médecine et Maladies Infectieuses. Sept 2020; 50(6, Supplement): S71. French. 